\title{
High-Energy-Density, Long-Life Lithium-Sulfur Batteries with Practically Necessary Parameters Enabled by Low-Cost Fe-Ni Nanoalloy Catalysts
}

Jiarui He, Amruth Bhargav, and Arumugam Manthiram*

Department of Mechanical Engineering and Texas Materials Institute, The University of

Texas at Austin, Austin, TX78712, United States

*e-mail: manth@austin.utexas.edu. 

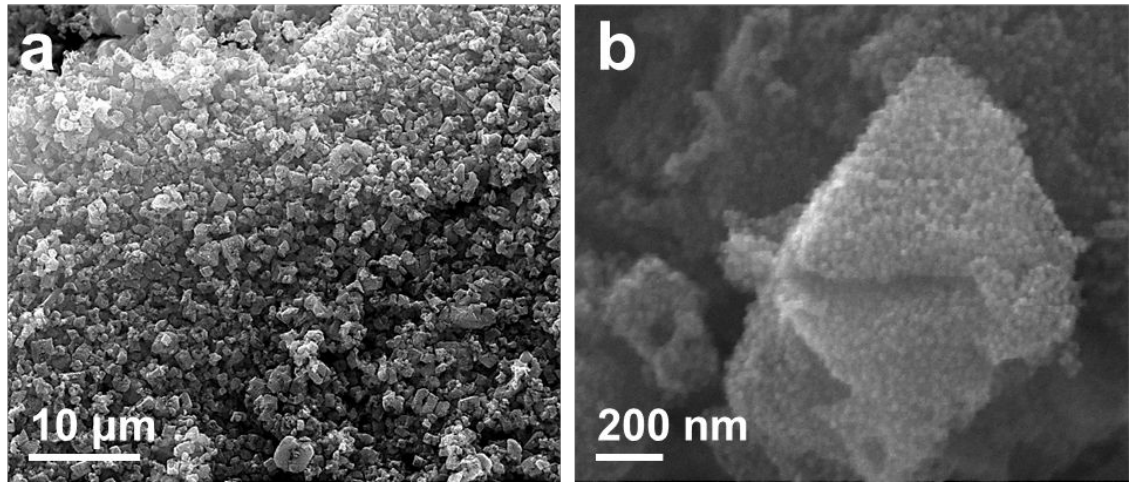

Figure S1. SEM images of Fe-Ni at different magnifications.
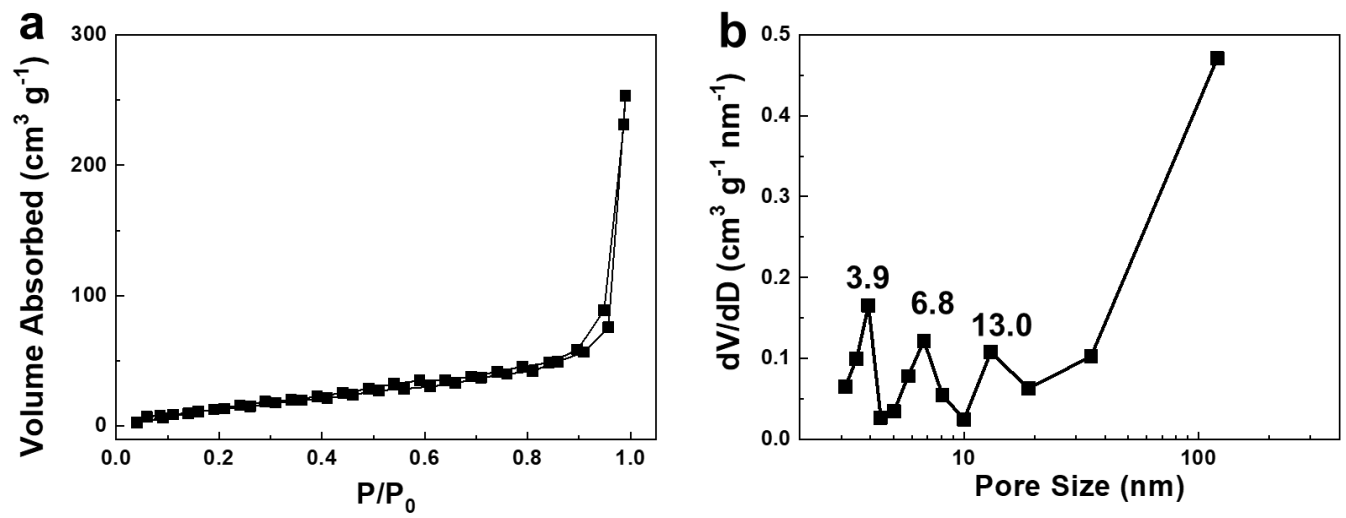

Figure S2. (a) $\mathrm{N}_{2}$ sorption isotherm and (b) pore size distribution of Fe-Ni. 

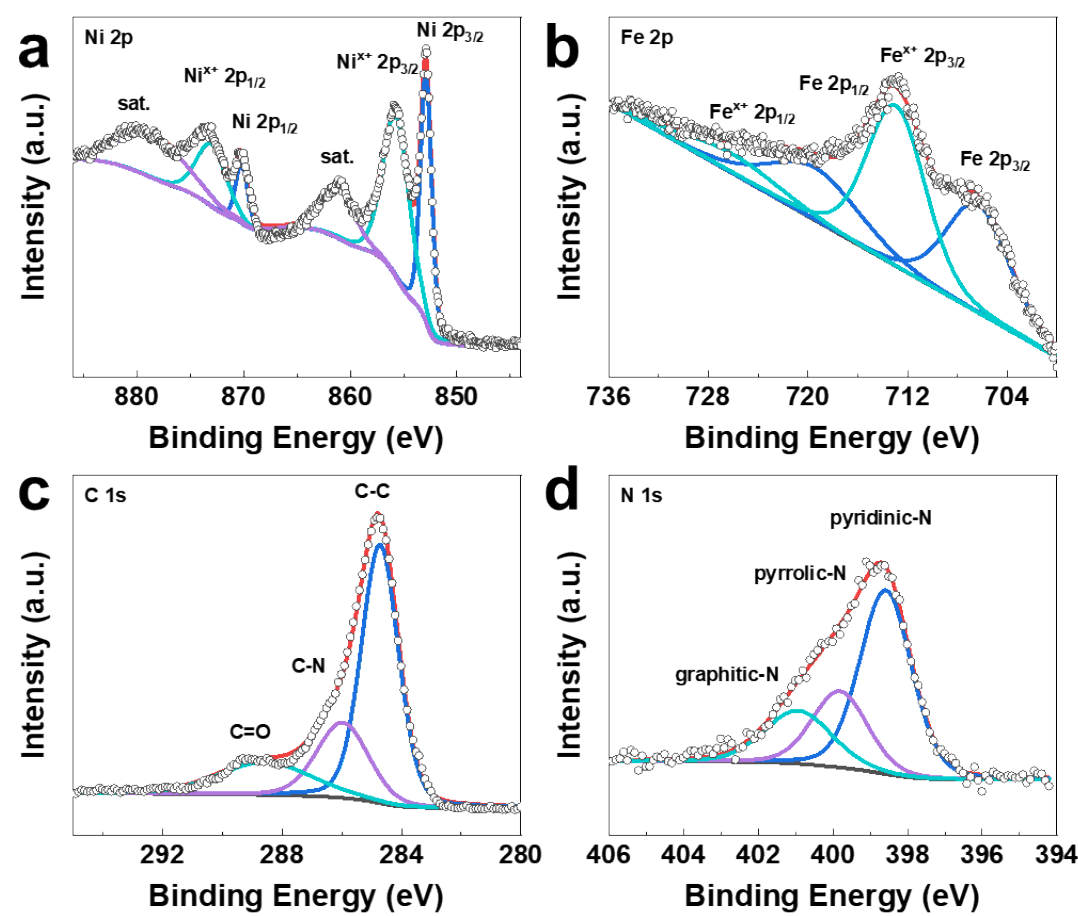

Figure S3. XPS study of the prepared Fe-Ni alloy. (a) High-resolution Ni2p spectrum, (b) Fe2p spectrum, (c) C1s spectrum, and (d) N1s spectrum. 

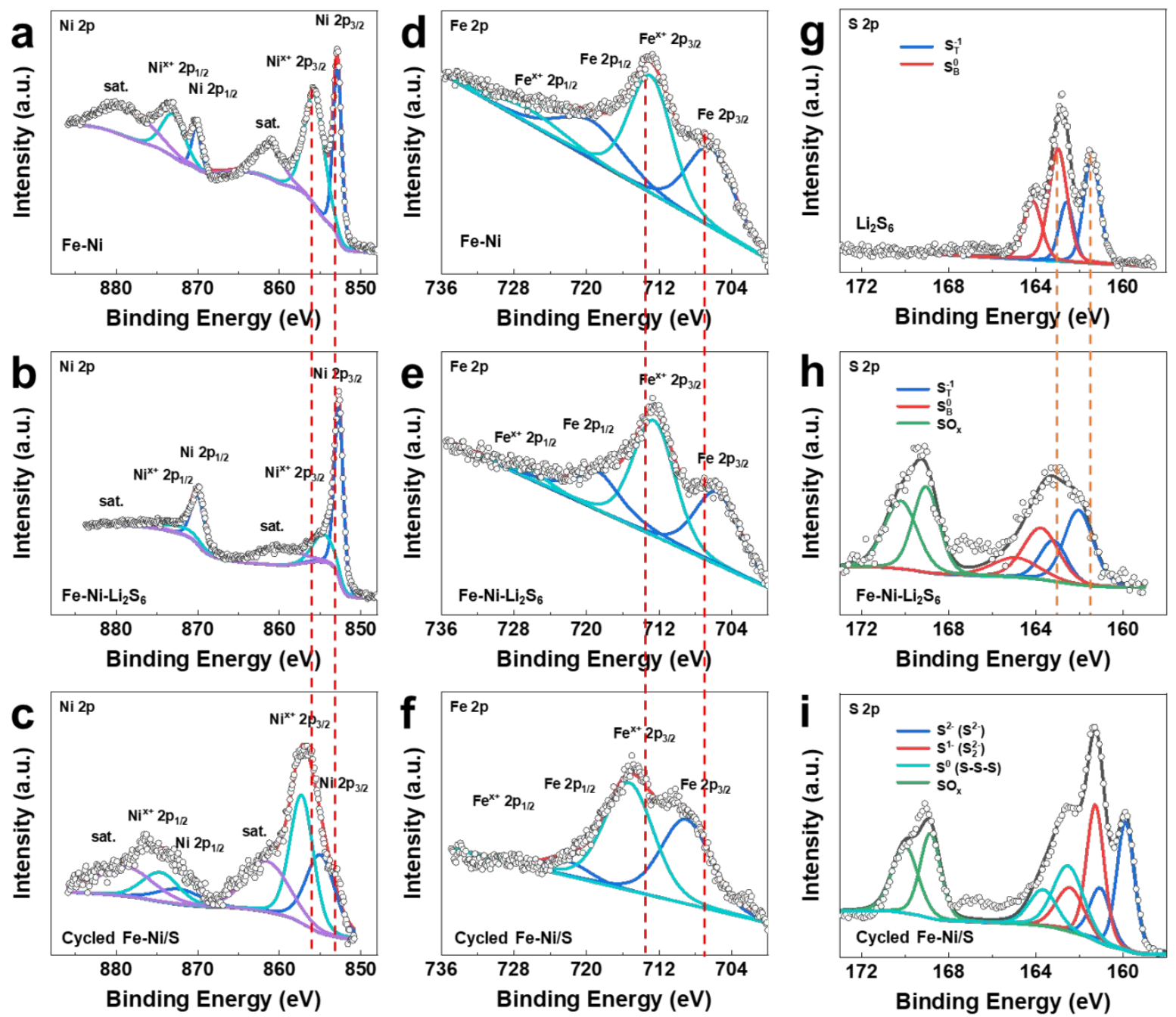

Figure S4. High-resolution Ni 2p spectrum of (a) Fe-Ni, (b) Fe-Ni contacting with $\mathrm{Li}_{2} \mathrm{~S}_{6}$, and (c) cycled Fe-Ni/S. High-resolution Fe 2p spectrum of (d) Fe-Ni, (e) Fe-Ni contacting with $\mathrm{Li}_{2} \mathrm{~S}_{6}$, and (f) cycled Fe-Ni/S. High-resolution $\mathrm{S} 2 \mathrm{p}$ spectrum of (g) $\mathrm{Li}_{2} \mathrm{~S}_{6}$, (h) Fe-Ni contacting with $\mathrm{Li}_{2} \mathrm{~S}_{6}$, and (i) cycled Fe-Ni/S at discharged state. 


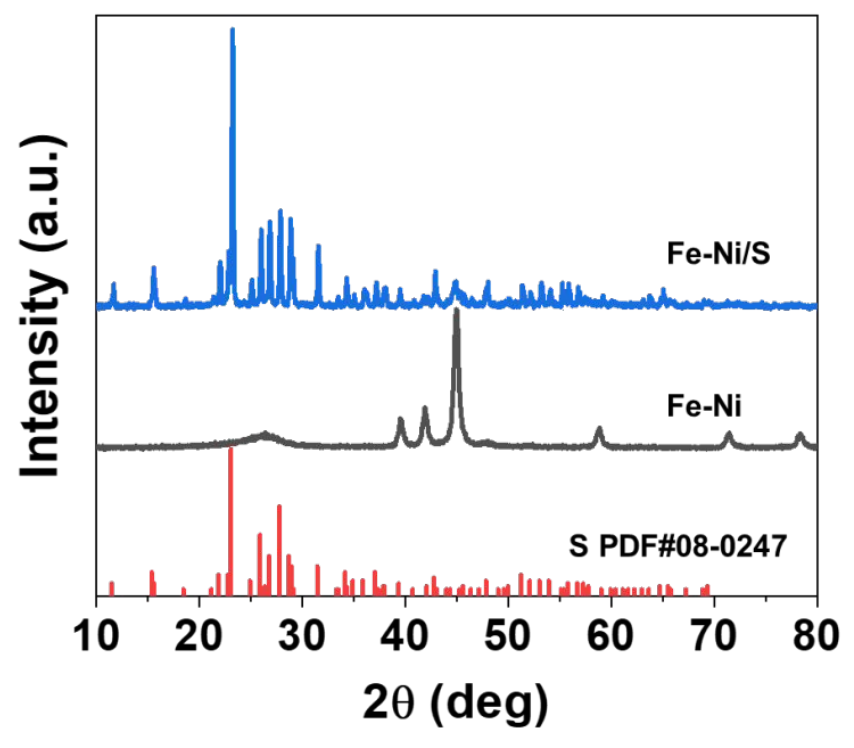

Figure S5. XRD patterns of $\mathrm{Fe}-\mathrm{Ni}$ and $\mathrm{Fe}-\mathrm{Ni} / \mathrm{S}$.
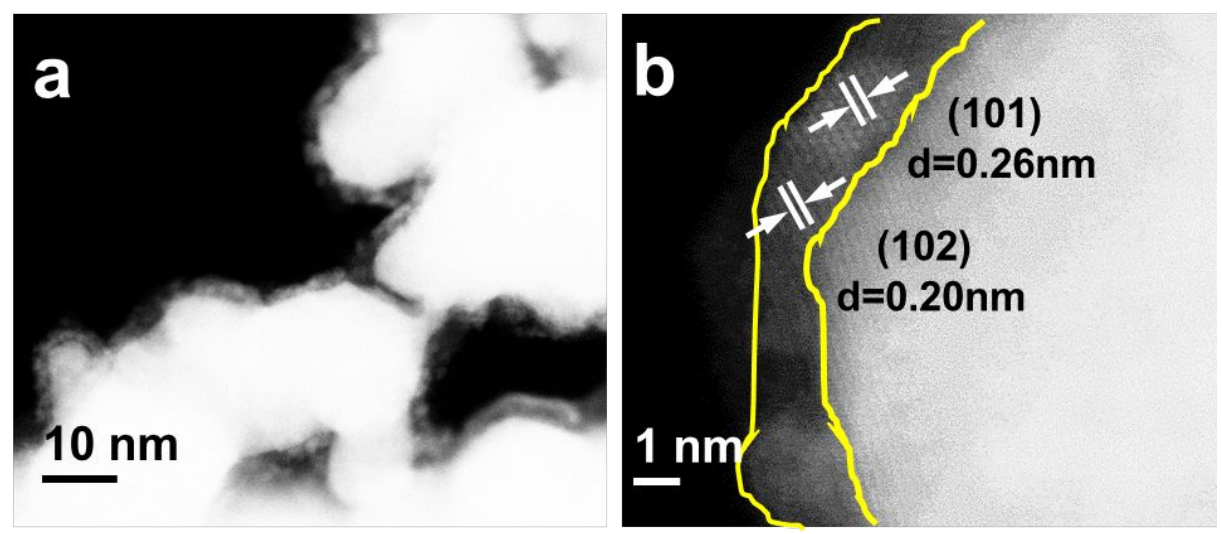

Figure S6. TEM morphology of $\mathrm{Fe}-\mathrm{Ni} / \mathrm{S}$ after intensive washing by $\mathrm{CS}_{2}$. The thin layer is $\mathrm{NiS}(\mathrm{PDF} \# 77-1264)$. 

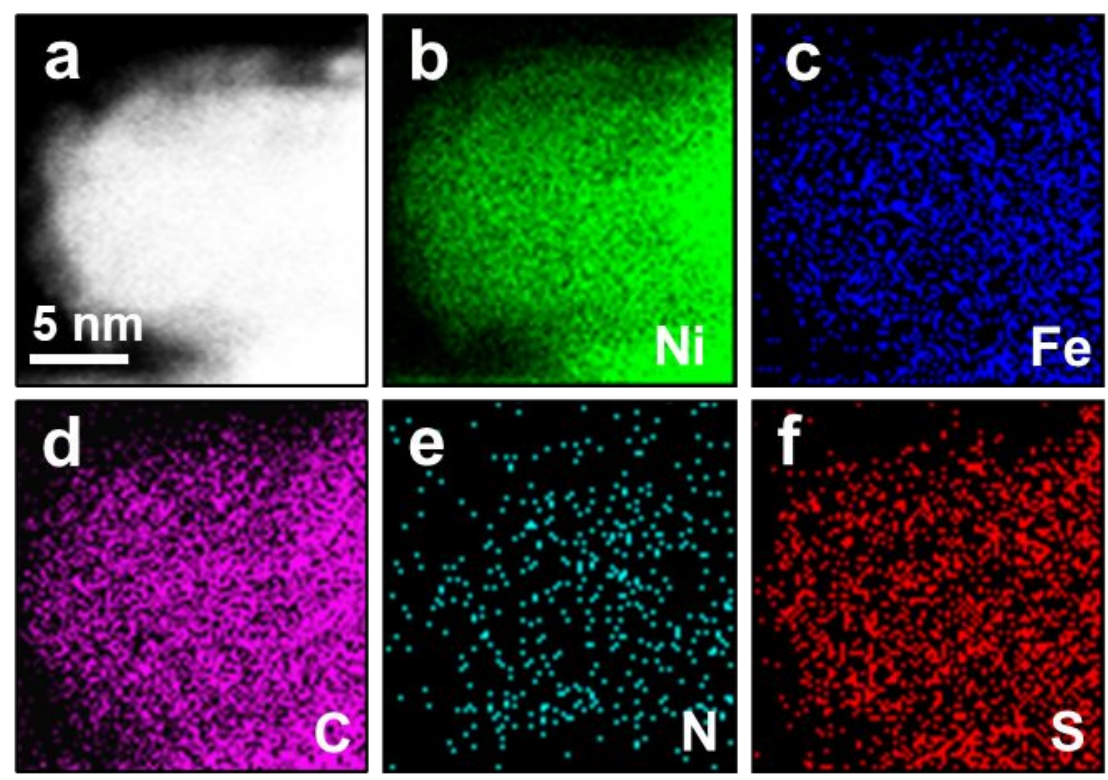

Figure S7. TEM morphology of $\mathrm{Fe}-\mathrm{Ni} / \mathrm{S}$ after intensive washing by $\mathrm{CS}_{2}$, and the corresponding elemental mapping images.
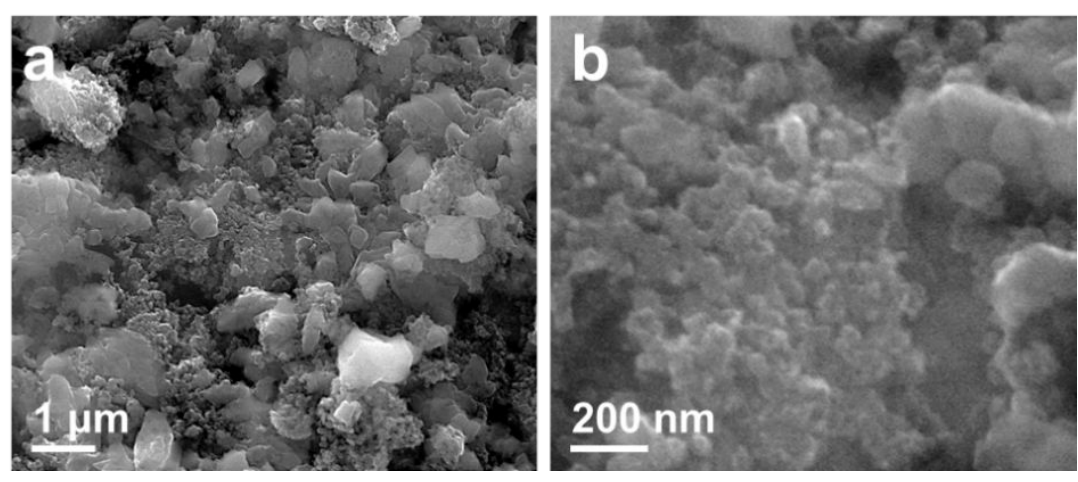

Figure S8. SEM images of Fe-Ni/S. 

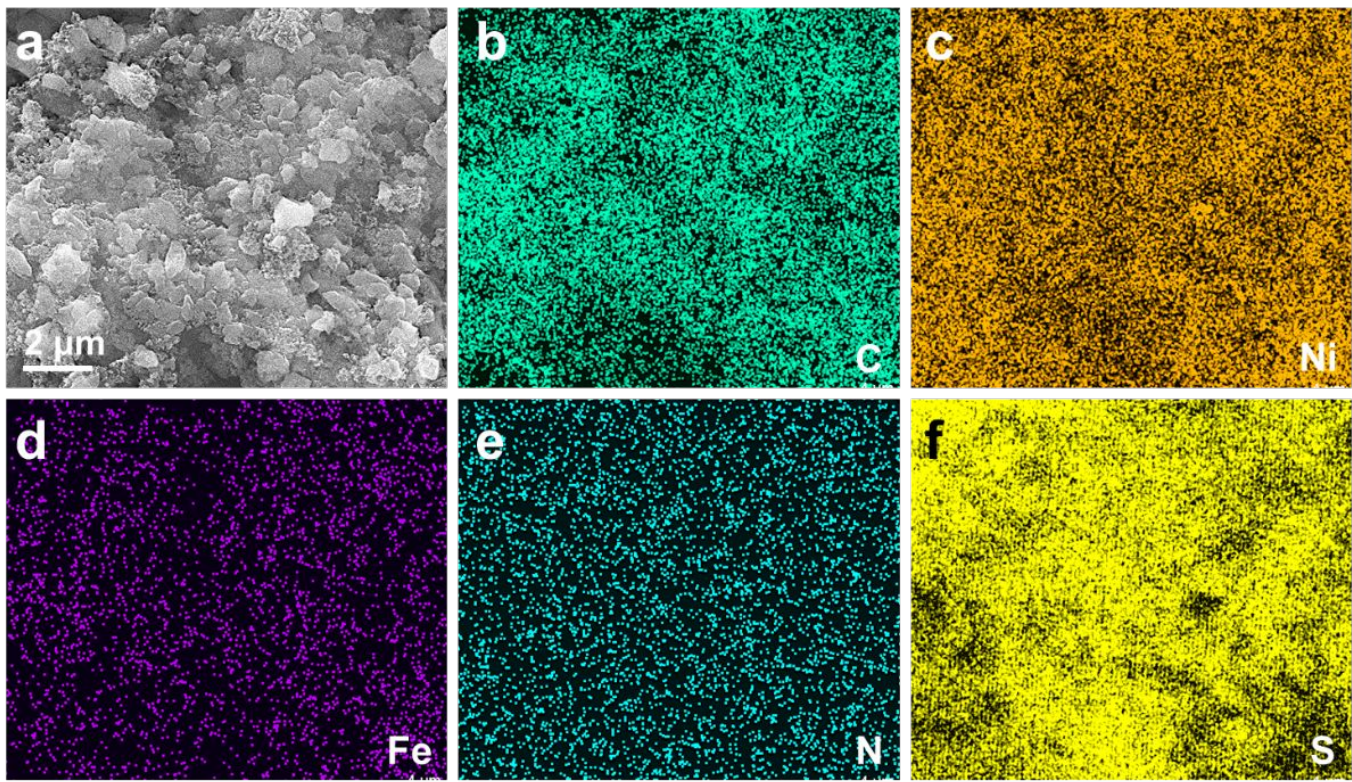

Figure S9. Elemental mapping images of $\mathrm{Fe}-\mathrm{Ni} / \mathrm{S}$.

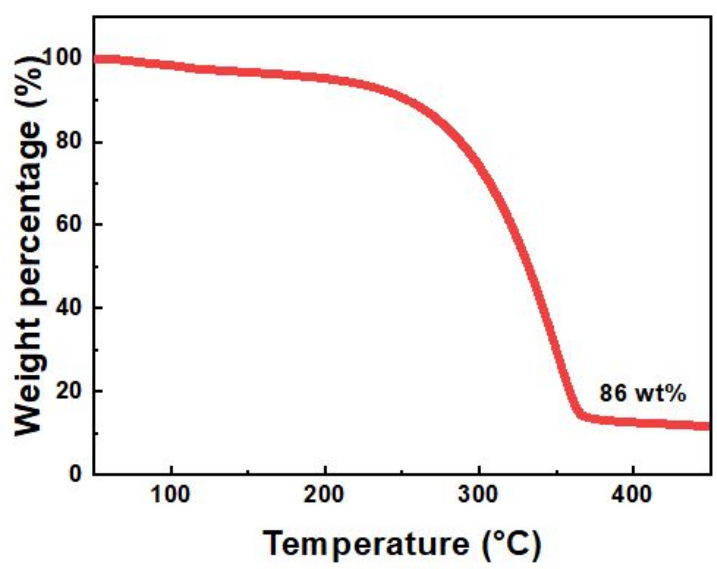

Figure S10. TGA profile of $\mathrm{Fe}-\mathrm{Ni} / \mathrm{S}$ in $\mathrm{N}_{2}$. 

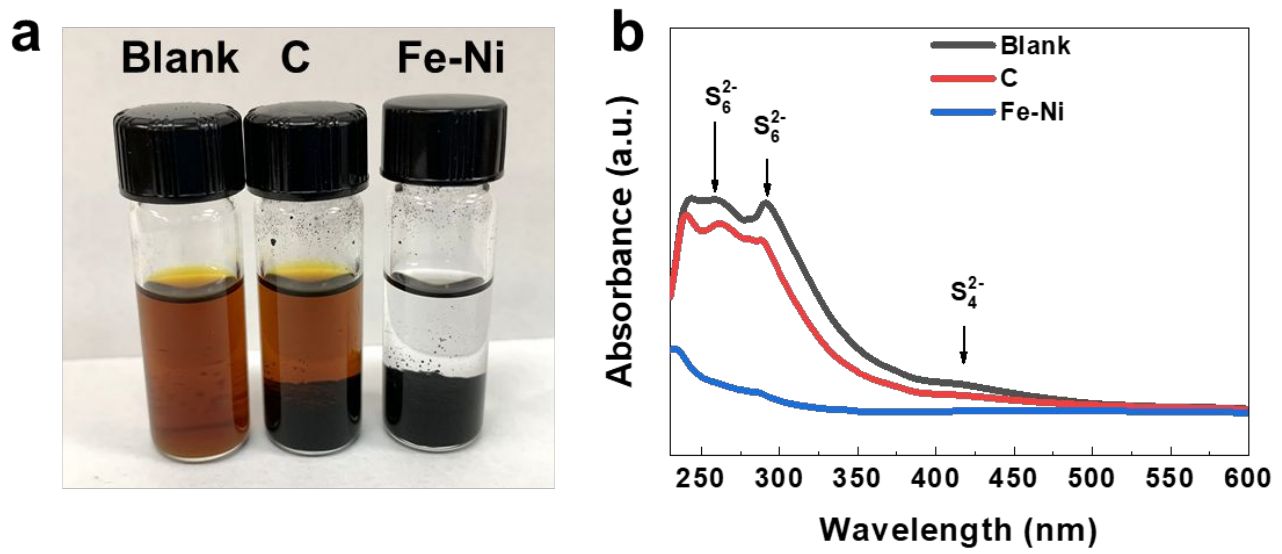

Figure S11. (a) Visible adsorption of $\mathrm{Li}_{2} \mathrm{~S}_{6}$ by pristine Fe-Ni and C. (b) UV-VIS spectra of the $\mathrm{Li}_{2} \mathrm{~S}_{6}$ solution with $\mathrm{Fe}-\mathrm{Ni}$ and $\mathrm{C}$.
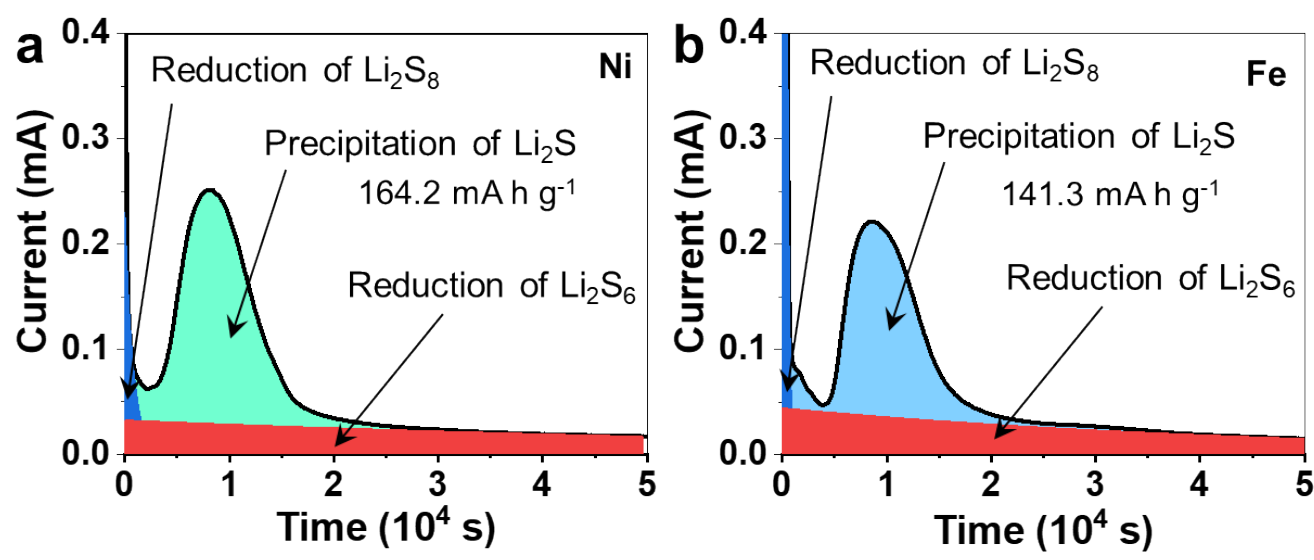

Figure S12. Chronoamperometry curves of $\mathrm{Li}_{2} \mathrm{~S}_{8} /$ tetraglyme solution, discharged to $2.05 \mathrm{~V}$ on (a) $\mathrm{Ni}$ and (b) Fe. The full discharge process was modeled mathematically as three parts according to the chronoamperometry curves: the dark blue area corresponds to the reduction of $\mathrm{Li}_{2} \mathrm{~S}_{8}$, the red region corresponds to the reduction of $\mathrm{Li}_{2} \mathrm{~S}_{6}$, and the light color field reflects $\mathrm{Li}_{2} \mathrm{~S}$ precipitation. 


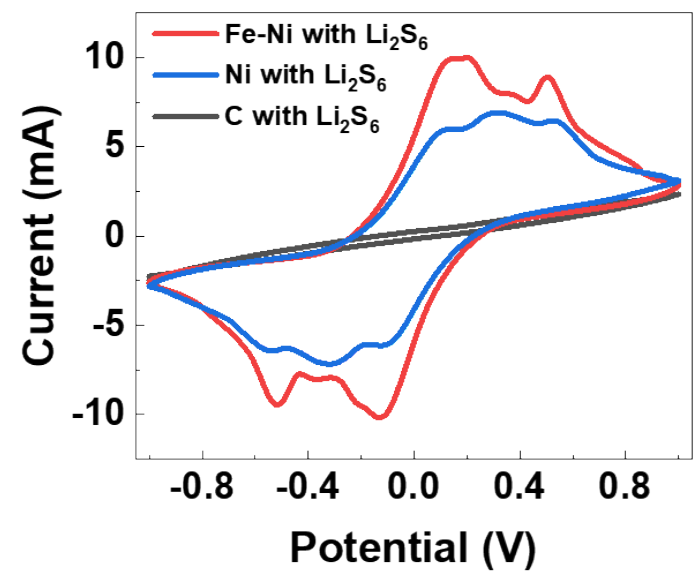

Figure S13. A comparative CV curves of the symmetric cells with identical electrodes of $\mathrm{Fe}-\mathrm{Ni}, \mathrm{Ni}$, and $\mathrm{C}$ in an electrolyte with $0.2 \mathrm{M} \mathrm{Li}_{2} \mathrm{~S}_{6}$ at $6 \mathrm{mV} \mathrm{s}^{-1}$.

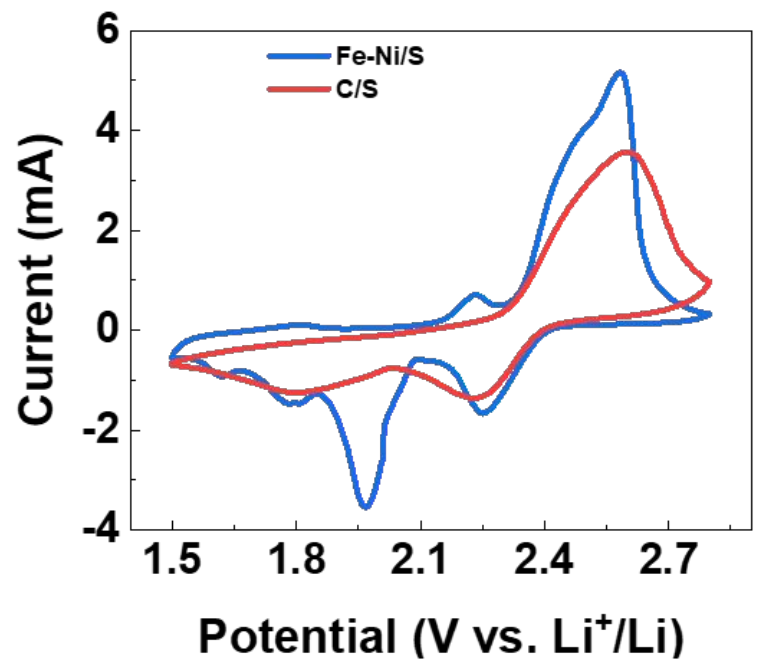

Figure S14. A comparative $\mathrm{CV}$ curves of $\mathrm{Fe}-\mathrm{Ni} / \mathrm{S}$ and $\mathrm{C} / \mathrm{S}$ cathodes. 

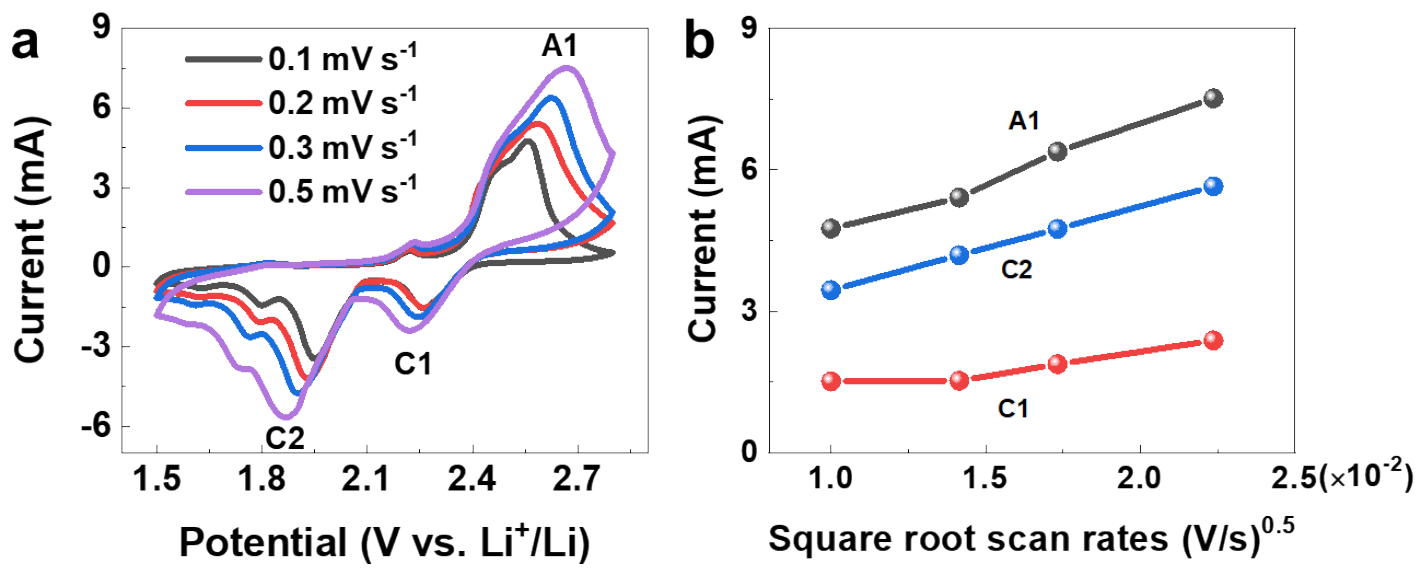

Figure S15. (a) CV curves of Fe-Ni/S cathodes under various scan rates. (b) Plot of CV peak current for the first cathodic reduction process $(\mathrm{C} 1)$, second cathodic reduction process (C2), and anodic oxidation process (A1) versus the square root of the scan rate.

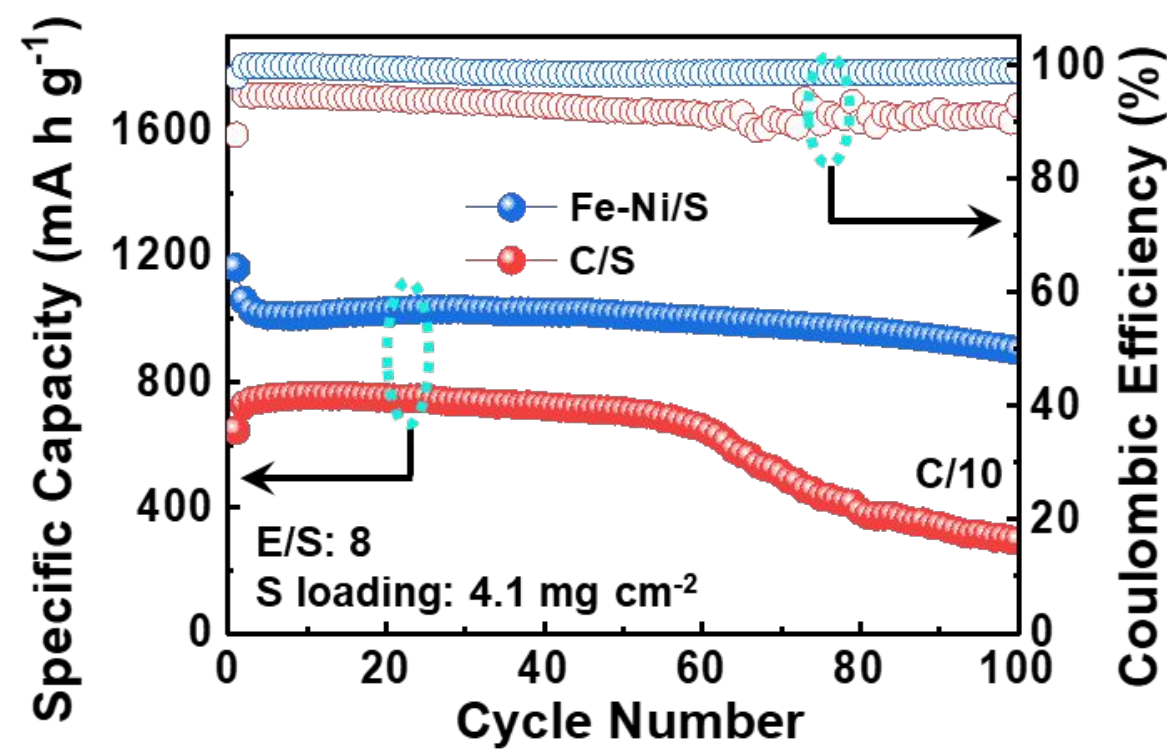

Figure S16. Cycling stability of Fe-Ni/S and C/S electrodes at C/10 rate for 100 cycles. 

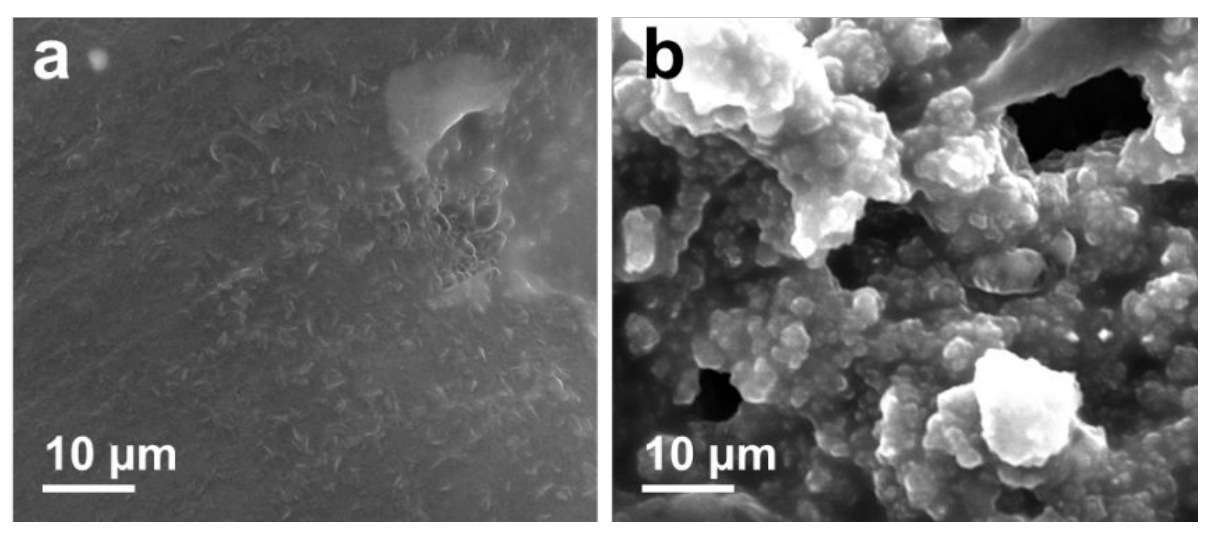

Figure S17. Morphologies of the cycled lithium foil paired with (a) $\mathrm{Fe}-\mathrm{Ni} / \mathrm{S}$ and (b) $\mathrm{C} / \mathrm{S}$.

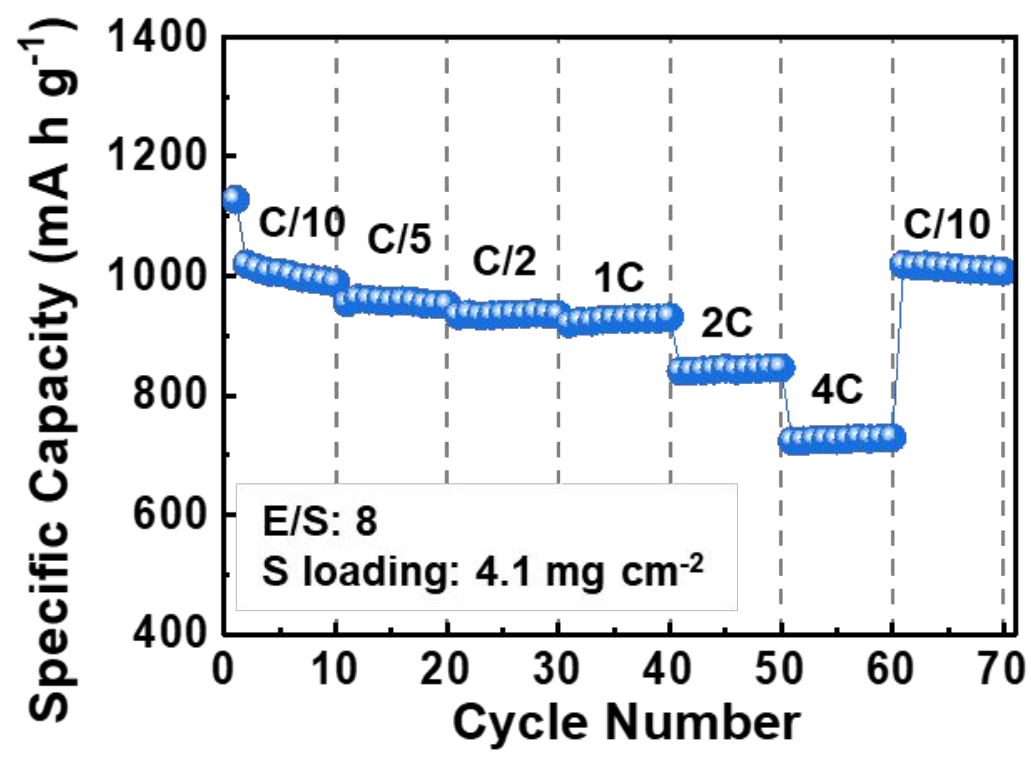

Figure S18. Rate performance of $\mathrm{Fe}-\mathrm{Ni} / \mathrm{S}$ cathode under various current densities. 


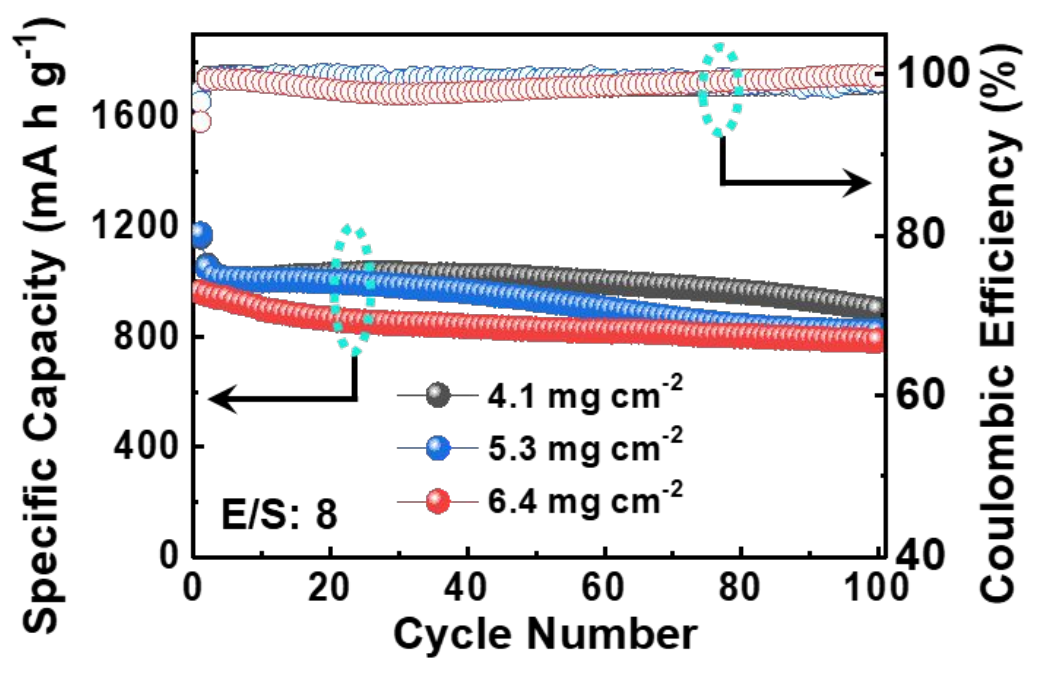

Figure S19. Cycling performance of the $\mathrm{Fe}-\mathrm{Ni} / \mathrm{S}$ electrodes with various sulfur loadings.
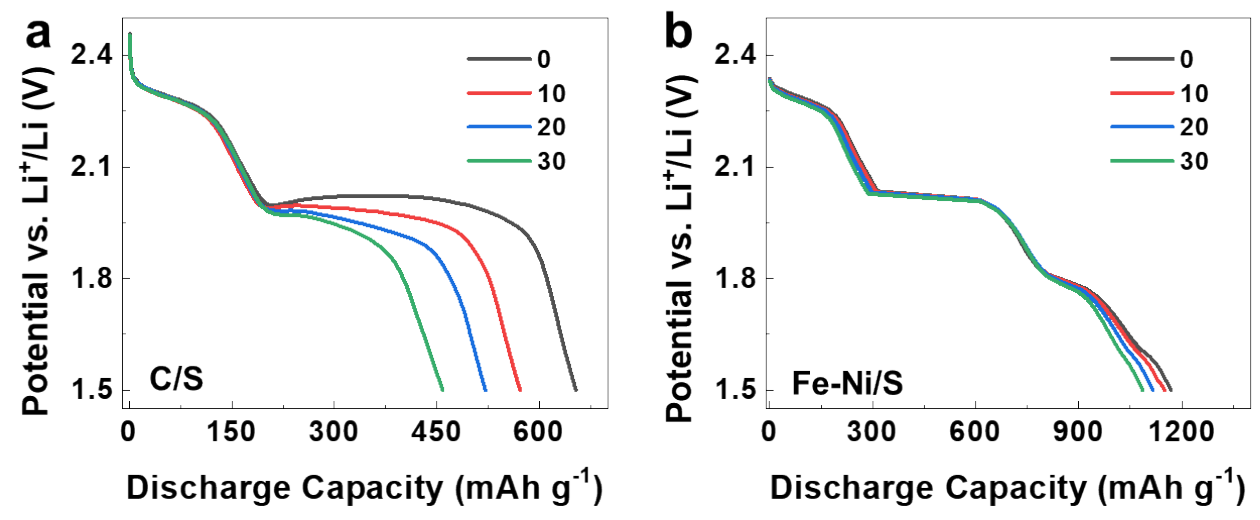

Figure S20. Self-discharge performance of $\mathrm{C} / \mathrm{S}$ and $\mathrm{Fe}-\mathrm{Ni} / \mathrm{S}$ electrodes at $\mathrm{C} / 10$ rate at room temperature. 